\title{
Gestão do patrimônio natural, histórico, arquitetônico e cultural: a experiência da Vila de Paranapiacaba
}

\author{
Paloma Albino Borba Cavalcanti ${ }^{1}$
}

RESUMO: Este artigo apresenta as estratégias de planejamento, implantação e consolidação de um projeto de valorização e gestão do patrimônio da Vila de Paranapiacaba. Os instrumentos de pesquisa utilizados foram a observação participante e entrevistas semi-dirigidas. O texto apresenta o contexto histórico e social que levaram a criação do Programa de Gestão do Patrimônio Natural, Histórico, Arquitetônico e Cultural da Vila , o Processo de implantação e consolidação do programa, os esforços da gestão do Programa para criar espaços de diálogo entre o governo e a sociedade civil e a discussão sobre o caráter inovador do Programa e os impactos deste na cidadania.

PALAVRAS CHAVE: Gestão Pública, Patrimônio Arquitetônico, Patrimônio Natural, Turismo, Cidadania ABSTRACT: This article presents strategies used in the process of planning and consolidating a project of management of the heritage village of Paranapiacaba. The research instruments were participant observation and semi-directed interviews. The text presents the historical and social context that led to creation of the Program for Management of Natural, Historical, Cultural and Architectural heritage of the Paranapiacaba village, the process of implementation and consolidation of the program, the efforts of the management of the program to create spaces for dialogue between government and civil society and finally presents the innovative character of the program and the impacts of this on citizenship.

KEYWORDS: Public Management, Architectural Heritage, Natural Heritage, Tourism, Citizenship

${ }^{1}$ Paloma Albino Borba Cavalcanti. Mestre em Administração Pública e graduada em Turismo pela ECA-USP. Coordenadora de Sustentabilidade na Sadia. Endereço: R. São Ludgero, 40, São Paulo - SP - 04722-060.

CADERNOS GESTÃo PÚBLICA E CIDADANIA, V. 12, N.51 - JUL./DEZEMBRO 2007 


\section{O contexto Histórico e Social}

Este artigo apresenta as estratégias de planejamento, implantação e consolidação de um projeto de valorização e gestão do patrimônio da Vila de Paranapiacaba. Os instrumentos de pesquisa utilizados foram a observação participante e entrevistas semi-dirigidas com 15 informantes: 03 moradores da vila, 04 gestores, 04 empreendedores locais e 02 profissionais envolvidos diretamente no Programa. Iniciaremos contextualizando historicamente a construção da Vila e as transformações que esta sofreu ao longo do tempo a seguir descreveremos o Programa de Gestão patrimonial criado pela prefeitura no ano de 2001 e os principais resultados obtidos por este Programa.

A Vila de Paranapiacaba foi construída para servir como moradia dos funcionários e base para as atividades desenvolvida pela São Paulo Railway Company, companhia inglesa responsável pela construção da ferrovia que ligava São Paulo ao litoral e porto de Santos. A parte alta da vila, com edificações de influência portuguesa, foi sendo construída a partir da fixação dos ex-funcionários da companhia que se aposentavam e permaneciam no local.

Com a saída da companhia, todas as casas (em torno de 350 imóveis - parte baixa) e a ferrovia foram entregues à RFFSA, que sem recursos para manter o mesmo grau de conservação, foi abandonando o patrimônio histórico ali existente. A partir da década de 1970, a Vila foi invadida por hippies e famílias pobres que não tinham condições de se sustentar e encontravam ali casas abandonadas onde era possível morar sem pagar aluguel, luz e água. Boa parte desses migrantes eram mulheres com muitos filhos que tinham sido abandonadas pelos maridos e uma população significativa de nordestinos. Esta característica socioeconômica ainda é marcante no perfil da população atual.

A Vila passou, durante as décadas seguintes, por um processo de deterioração, alto grau de intervenção no patrimônio (construção de "puxadinhos" e anexos nas casas) e aumento da criminalidade (segundo relatos dos moradores, ali encontrava-se uma base do PCC e se tornara ponto importante de distribuição de drogas), devido ao seu isolamento é preciso passar por três municípios - Mauá, Ribeirão Pires e Rio Grande da Serra para chegar à Vila e a falta de segurança. Para lidar com todos estes problemas foi criado em 2001 um programa de recuperação e preservação do patrimônio histórico e natural aliado ao desenvolvimento econômico, orientado pelos princípios de inclusão social e 
empreendedorismo. O Programa foi idealizado juntamente com a criação da Sub-prefeitura de Paranapiacaba e Parque Andreense, órgão diretamente responsável pelo programa. Seu início efetivo deu-se com a compra da Vila pela prefeitura de Santo André, em 2002.

No momento da concepção do programa, havia inúmeros problemas sociais, principalmente um alto índice de desemprego, alcoolismo, os jovens sem perspectivas de futuro e envolvidos com drogas e outra parte da população tendo que se deslocar grandes distâncias para trabalhar nos centros urbanos próximo.Dessa forma, o programa foi concebido para aliar à preservação do imenso patrimônio histórico e natural a uma possibilidade de desenvolvimento econômico que gerasse renda e empregos na própria Vila, resgatando a auto-estima da população e promovendo a inclusão social. Isso foi feito através do desenvolvimento da atividade turística, concebida nos moldes do empreendedorismo social, ou seja, incentivando a própria comunidade a abrir seus negócios através do projeto "Portas Abertas". Ao mesmo tempo, era preciso ordenar a ocupação e regularizar o uso dos imóveis, o que em um primeiro momento, causou um estado de tensão social e desconfiança da comunidade em relação à prefeitura, que efetivamente tinha a tarefa de assumir a gestão do local.

Em parceria com a polícia civil, aos poucos os grupos de atuação criminosa foram sendo retirados e parte da população que se recusava a aceitar as novas condições de uso dos imóveis. Houve uma certa requalificação do perfil da população e do próprios turistas, com redução inclusive do número de habitantes (em 2000, a parte baixa tinha 1.100 habitantes e em 2005 apenas 898 habitantes). O termo de concessão do uso dos imóveis foi elaborado no nome das mulheres e são concedidos uma série de descontos nos aluguéis para a população envolvida nos projetos turísticos e sociais da sub-prefeitura, bem como naqueles que invistam na restauração do imóvel.

Por fim, ações de educação ambiental e a criação do Parque Municipal de Proteção Ambiental Integral garantiram a preservação do patrimônio natural e o desenvolvimento de ações para captação de turistas permitiu o desenvolvimento dos empreendimentos turísticos. 


\section{O Processo de implantação e consolidação do programa:}

A fase de implantação é marcada pelo trabalho de regularização fundiária e a busca de estabelecer uma relação amigável com a população local. As demais ações desta fase concentraram-se em criar procedimentos administrativos e institucionais de gestão do patrimônio natural e cultural, iniciar o desenvolvimento turístico planejado e o processo de restauro do patrimônio, com a recuperação de quatro imóveis.

Trata-se de um programa que apresenta significativo grau de complexidade de intervenção sobre a vida da comunidade e sobre o próprio patrimônio.O Programa está em fase de consolidação ${ }^{2}$, tanto em relação aos projetos e ações empreendidas, quanto ao modelo de gestão (inclusive dos canais participativos). O orçamento anual gira em torno de R\$5.776.365,87 (média entre 2001 e 2004) provenientes do poder público e do Fundo de Paranapiacaba. A estes recursos somam-se mais $\mathrm{R} \$ 2.723 .126,37$ oriundos de organismos multilaterais, empresas e entidades.

O orçamento anual do programa é significativo: a maior parte do orçamento da subprefeitura (que corresponde a 3\% do orçamento total do município) é aplicado na Vila de Paranapiacaba, o que segundo o próprio sub-prefeito, representa um grande esforço por parte da administração pública em recuperar a área, acreditando no desenvolvimento econômico através do turismo. A média de gastos anuais (entre 2001 e 2004) advindas do tesouro foi de $\mathrm{R} \$ 5.371 .256,83$, correspondendo a $93 \%$ dos recursos do orçamento do programa. Os $7 \%$ restantes advém da receita do Fundo de Paranapiacaba (FUNGEPHAPA - Fundo de Gestão do Patrimônio Histórico e Ambiental de Paranapiacaba), gerada pelos aluguéis das antenas de transmissão, aluguéis das casas da Vila e doações de particulares, perfazendo um total de $\mathrm{R} \$ 405.109,04$. Além destes recursos, também houve aporte financeiro de agências multilaterais, empresas e verbas de pesquisa, entre elas: a Agência Canadense para o Desenvolvimento Internacional ( $\mathrm{R} \$ 405.025,33)$, Universidade British Columbia ( $\mathrm{R} \$ 268.175,00)$, Petrobrás e Instituto Ecoar para a Cidadania $(\mathrm{R} \$ 1.300 .000,00)$, WMF - World Monuments Fund e American Express ( $\$ 450.000,00)$ e verbas para a pesquisa da FSA - Fundação Santo André e FAPESP (R $\$ 300.000,00)$. Anualmente é

\footnotetext{
${ }^{2}$ Estes dados foram coletados em pesquisa realizada em 2005.
} 
realizado um trabalho de captação de patrocínios para realização do Festival de Inverno de Paranapiacaba, um dos projetos que visam a aumentar a visitação turística Vila.

Com relação a perspectivas de custos, o programa demandará certamente ainda um significativo montante devido principalmente à demanda de restauro existente na vila. Entretanto, a captação dos recursos ainda é escassa e boa parte das parcerias estabelecidas não apresenta um caráter de continuidade e de efetiva co-gestão. A falta de recursos foi uma dificuldade citada de forma recorrente em todas as entrevistas realizadas com a equipe da prefeitura. Segundo a responsável pela captação de recursos faz-se necessário realizar um trabalho de cunho institucional, diferentemente do que vinha sendo desenvolvido anteriormente, que estava focado na captação de negócios e investimentos da iniciativa privada para o setor turístico. Para tanto, a captação é segmentada em três frentes - recursos nacionais, internacionais e empresariais. Os recursos nacionais são captados através da participação de concursos via apresentação de projetos, já os internacionais são voltados para programas e ações maiores.

Quanto aos recursos empresariais, a dificuldade é compatibilizar o tipo de desenvolvimento a que se propõe o programa, que não contempla grandes empreendedores se estabelecendo na Vila e a captação de recursos.O desenvolvimento das ações concentram-se na elaboração de eventos que estimulam a vinda de patrocinadores e estuda-se a criação de um Selo, que reconheça a participação em ações públicas. Entretanto, concretamente a única fonte de recursos regular até o momento são público.Dessa forma, a auto-sustentabilidade do programa no que tange aos recursos ainda é problemática.

\section{A Gestão do programa: a articulação sociedade civil e governo local}

O programa é gerenciado pela sub-prefeitura de Paranapiacaba e Parque Andreense e, mais especificamente pela Diretoria de Paranapiacaba. Os sub-departamentos da diretoria que estão quase que exclusivamente envolvidos com o programa são a Gerência de Recursos Naturais, Projetos e Estudos Patrimoniais e Turismo. Além destas gerências, as de Assistência Social e Captação de Recursos também estão parcialmente dedicadas ao programa. São também articuladas ações em diversos departamentos da prefeitura de Santo André, como o de físcalização, obras, educação e a gerência administrativa.

CADERNOS GESTÃo PÚBLICA E CIDADANIA, v. 12, N.51 - JUL./DEZEMBRO 2007 
Há uma série de parcerias para ações específicas dentro do programa. Elas ocorrem, na maioria das vezes, no âmbito do desenvolvimento de pesquisas e qualificação de mão-deobra, como é o caso do Instituto Florestal (para o programa de jovens), Sebrae, ABL associados, Reserva da Biosfera Cinturão Verde, Instituto Ecoar, IPHAN, CONDEPHAAT, Escola Técnica Júlio Mesquita, entre outros.

O envolvimento da comunidade já é significativo em todo o programa de gestão. Parte deste envolvimento ocorre através da participação nos canais participativos criados localmente, entre eles o Conselho de Representantes e o FUNGHEPAPA. Embora o primeiro seja voltado às discussões de todas as ações da sub-prefeitura, incluindo o Parque Andreense, foi formada a Câmara Técnica de Paranapiacaba e esta sim acaba captando boa parte das demandas da comunidade no que tange ao programa. Já o segundo canal é efetivamente voltado à realidade da Vila, sendo que a eleição dos membros representativos da comunidade é feita através de votação.

Além destes canais de participação, existem importantes parcerias com a sociedade civil e iniciativa privada. Todas as associações e empresas de monitoria ambiental ajudam ativamente na fiscalização do parque e realizam trabalhos voluntários para receber escolas públicas (serviço agendado pela própria prefeitura). Existem também a SPR - Sociedade de Preservação e Resgate de Paranapiacaba (que ajuda na fiscalização e controle dos imóveis), a Associação de Empreendedores do Setor de Alimentos e Hospedagem, o Núcleo Comunitário de Cerâmica e Vidro (onde são realizados cursos gratuitos, especialmente para as mulheres) e o Centro Cultural Câmara Cascudo (que realiza diversas atividades para resgate da identidade histórica da Vila e de conscientização e desenvolvimento cultural).

Com relação aos conflitos, embora haja um consenso de que o programa trouxe enormes benefícios à Vila, existe um quadro de diversidade de interesses e divergências quanto à maneira de gerenciamento de alguns departamentos. Os grupos mais arraigados à Vila e às casas onde residem ainda resistem em aceitar as intervenções e a frequente fiscalização por parte da prefeitura, por exemplo. Muitos acham que por vezes a gestão é autoritária e impositiva, apesar da existência dos conselhos. Boa parte da sociedade civil entrevistada aponta a necessidade de maior articulação e participação quanto às ações da gerência de projetos e estudos patrimoniais e a gerência de turismo. 
O desenvolvimento turístico traz muitos benefícios aos empreendedores, porém com o aumento da movimentação, parte dos moradores começa a reclamar do agito e do barulho, especialmente no Festival de Inverno, que é reponsável pela captação de praticamente metade dos visitantes anuais à Vila em um único mês. Também há divergência na aplicação dos recursos do Fundo de Paranapiacaba (FUNGHEPAPA) e no zoneamento que vêm sendo discutido para a Vila.

O que se pode retratar como quadro geral é que a partir da implantação da sub-prefeitura e início da implantação do programa houveram avanços significativos na relação da sociedade civil com o poder público e com os próprios agentes. O que em um primeiro momento revela-se como um relação tensa e desconfiada, hoje parece conseguir somar esforços, embora em um contexto de divergência.

Antes havia muito medo por parte da população em reclamar ou se pronunciar em relação às ações feitas, pois temiam pela perda de suas casas e pela expulsão. A partir do momento em que passaram a sentir segurança de que podiam participar das discussões sem o temor de serem expulsos, toda a comunidade se pronuncia, debate e formula, formal ou informalmente cada ação do programa, havendo efetivamente uma incorporação do mesmo no seu cotidiano, tamanha a transformação que vem promovendo.

O sub-prefeito reserva um dia da semana para receber pessoalmente membros da comunidade e há uma relação direta entre a mesma e cada um dos envolvidos no programa, até mesmo pelo tamanho da Vila. Por isso mesmo, muitas ações acabam se tornando até mesmo personalistas e em muitos depoimentos as pessoas mencionaram claramente os nomes daqueles que estavam sendo autoritários ou incompetentes.

Apesar de todos os avanços é preciso ressaltar o desenho institucional e sua normatização precisa ser revisto para prever uma maior institucionalização da participação da comunidade no processo de co-gestão. Os órgãos participativos hoje são somente consultivos e a representatividade dos diversos interesses da comunidade ainda é pequena, pois as vagas ainda são poucas. E as demandas que hoje são atendidas individualmente devem ser mais transparentes aos demais grupos de pressão, para não criar a impressão de favorecimento de certas agendas 


\section{Resultados alcançados}

Os resultados alcançados são visíveis: a Vila está bem conservada, os serviços de limpeza urbana, segurança, iluminação, educação e saúde funcionam a contento e o número de empreendimentos turísticos é crescente. Os visitantes vêm aumentando ano a ano, houve geração de empregos e renda no local, há envolvimento de parte dos jovens na atividade turística (possível através do PJ - Programa de Jovens de capacitação para monitoria ambiental e cultural) e uma gradativa melhoria da imagem de Paranapiacaba junto ao mercado turístico (antes tida como um local que oferecia riscos aos visitantes).

Em relação aos objetivos de preservação do patrimônio histórico, pode-se destacar como resultados a restauração de alguns imóveis na Vila (cinco ao todo), o aumento da conscientização da população sobre a importância da preservação destes imóveis e o retrocesso do processo de degradação da Vila. A gestão se revela muito eficiente, estabelecendo normas de uso e fiscalização constante, entretanto o programa ainda apresenta certa deficiência em termos de efetividade ao que se propõe. Isso porque existe escassez de recursos públicos para a restauração, dificuldade em conseguir financiamentos ou doações nesse montante e a população que ocupa as casas não tem recursos para investir na recuperação dos imóveis.

Já em relação à preservação do patrimônio natural, vale ressaltar a criação do Parque Municipal Nascentes de Paranapiacaba em 2003, área de proteção integral com 4,3 milhões de $\mathrm{m}^{2}$, em que se passou efetivamente a controlar a visitação à Mata Atlântica. Isso permitiu que as atividades ilegais realizadas (como extração de plantas e desmatamento) e a visitação depredatória fossem interrompidas, pois o acesso ao parque só é permitido com a presença dos monitores ambientais.

Outros resultados nessa área que merecem destaque são o trabalho de formação de monitores ambientais (em torno de 50 jovens já foram qualificados) através do Programa de Jovens, em parceria com o Governo do Estado de São Paulo (Instituto Florestal) e o aumento significativo da consciência preservacionista da população. Muitas metas ainda precisam ser alcançadas, dentre elas assumir com mais efetividade o processo ecológico na Vila (gestão de resíduos, reciclagem, etc) e trazer a pesquisa científica, para que seja 
possível identificar e mapear as espécies da flora e fauna locais, estabelecendo planos para recuperação.

No que tange aos resultados sociais e econômicos que o programa vêm atingindo pode-se ressaltar: 356 habitantes envolvidos diretamente nos programas de turismo $(25,11 \%$ da população total de 1418 habitantes em 2000); 60\% das pessoas beneficiadas são mulheres; diminuição da taxa de desemprego (de 63\% em 1999 - levantamento FAU para 32\% em 2005 - levantamento prefeitura); Crescimento da renda média individual de $\mathrm{R} \$ 150,00$ em 2001 para R\$266,00 em 2005; Aumento do número de jovens matriculados no segundo grau (de 20,21\% em 1999, para 53,56\% em 2005); Fixação da População Residente (que antes do programa era altamente rotativa e sem raízes) - em 1999, 40\% da população vivia há menos de três anos em Paranapiacaba e em 2005, somente $24 \%$.

No que tange ao desenvolvimento de serviços turísticos, houve aumento do número de empreendimentos, indo de 07 em 1999, para 74 em 2005 (sendo 41 na área de alimentação, 13 na área de hospedagem e 20 de serviços como agências recptivas, ateliês-residência, entre outros). Entretanto, mesmo com a implantação do selo de qualificação turística e a certificação de 22 empreendimentos, a qualidade dos serviços é baixa e poucas empresas são regularizadas.

A visitação subiu de 41.000 pessoas em 2001 para 200.000 mil pessoas em 2005 (Estimativa), o que representará em torno de $70 \%$ da meta estipulada no programa. Grande parte dessa visitação ocorre em função de um único evento ( $O$ Festival de Inverno), gerando problemas de sazonalidade (muitos turistas em um único período do ano, enquanto em outros pouca visitação).

Por fim, em relação à comunidade como um todo, pode-se destacar o aumento da aceitação da população de Santo André quanto a Paranapiacaba e um sentimento de pertencimento dos habitantes da Vila ao município. Houve aumento significativo do envolvimento da população com a gestão do programa através da participação nos Conselhos e mesmo informalmente, através da realização de reuniões e conversas com a equipe da subprefeitura. 


\section{Considerações Finais}

Antes de finalizar, gostaríamos destacar dois aspectos do Programa; o caráter inovador desta experiência e o impacto sobre a cidadania. Todo o patrimônio histórico-arquitetônico de Paranapiacaba pertence ao setor público, o que de um lado facilita o trabalho de recuperação e controle sobre o uso dos imóveis, mas de outro cria uma relação muito específica entre o poder público e a sociedade civil, que embora fixada na área há muito mais tempo passa a responder diretamente à prefeitura, passando à condição de "inquilinos" da mesma. É inovador o estabelecimento de um programa de desenvolvimento econômico através do turismo que trabalhe de maneira tão integrada a questão da inclusão social, construção da cidadania, resgate da auto-estima e construção de uma identidade cultural por parte da população. Esse se constitui em um fator importante para a sustentabilidade do programa, na medida em que a população passa a se apropriar do patrimônio cultural e da história local.Tudo isso aliado a uma atuação e coordenação muito forte por parte da prefeitura. Esse controle sobre o desenvolvimento da atividade turística só foi possível graças à posse dos imóveis, o que deixa o programa em uma condição singular de implantação. Caso contrário, é provável que começasse a existir na Vila um movimento de especulação imobiliária, a vinda de investidores externos e certa ocupação desordenada.

A gestão do patrimônio natural também é inovadora, na medida em que são poucos os municípios que se propõem a criar um Parque Municipal de Preservação Ambiental Integral (esta condição impossibilita qualquer nova construção na área tombada), colocando em condições de equiparidade de preservação o patrimônio cultural e ambiental. A participação da sociedade e dos monitores ambientais foi significativa na formulação do parque e no seu Plano de Manejo (em andamento). Foram construídas guaritas e o livre acesso da comunidade é possível através da apresentação da carteirinha de usuário, gratuita, sendo obrigatória o pagamento da entrada somente aos turistas. Isso também é de certa maneira incomum na gestão de áreas naturais, já que é difícil o entendimento de que o uso do patrimônio ambiental pela comunidade é também é uma forma de torná-los agentes ativos na preservação, oferecendo também uma opção de lazer importante a uma população carente. 
O programa promove o exercício da cidadania, na medida em que o grau de intervenção a que se propõe é alto, exigindo um inevitável debate e envolvimento da comunidade sobre as ações da prefeitura. $\mathrm{Na}$ medida em que se constroem canais de diálogo e que se começam a enxergar os resultados, as pessoas se sentem estimuladas a participar e a se tornarem agentes ativos na vida de sua comunidade. Dessa forma, é possível perceber que a população assumiu o desafio da participação e do exercício dos direitos e passou a se articular cada vez mais, constituindo diversos grupos de pressão organizados.

Os benefícios diretos para grupos vulneráveis como as mulheres e os jovens promovem a inclusão social e resgaste da auto-estima dessas pessoas. Além disso, a aceitação mútua entre a população de Santo André e a de Paranapiacaba promove a integração do território do município e cria um sentimento de "pertencimento" por parte da comunidade local. Primeiro, pelo resgate de uma identidade cultural que lhe permite dizer com orgulho que hoje mora em Paranapiacaba, o que antes era motivo de vergonha pela situação em que a Vila se encontrava e segundo, pelo efetivo exercício de sua condição como morador da cidade de Santo André. 


\section{Referências Bibliográficas}

CASTILLO-RUIZ. Hacia una nueva definición de patrimonio histórico? PH Boletín del Instituto Andaluz del Patrimonio Histórico, Sevilla: IAPH, n.XVI, sept. 1996, Critérios Sociais para Locação de Imovéis em Paranapiacaba. Prefeitura de Santo André. Autor. 2005.

Estudos Preliminares e Diagnóstico para Zoneamento da Vila previsto no Plano Diretor de Santo André. Prefeitura de Santo André . Autor 2005

JELIN, E. Cidadania e alteridade: o reconhecimento da pluralidade. Revista do patrimônio, Rio de Janeiro: Iphan, 1996.

Plano Estratégico de Desenvolvimento Turístico da Vila de Paranapiacaba. Prefeitura de Santo André - 2002

Sumário de Dados de Paranapiacaba e Parque Andreense. Prefeitura de Santo André. Autor 2002 e 2004; 